\title{
Deoxycytidine Analogue TAS-109
}

National Cancer Institute

\section{Source}

National Cancer Institute. Deoxycytidine Analogue TAS-109. NCI Thesaurus. Code C82697.

An analogue of the nucleoside deoxycytidine with potential antineoplastic activity.

Nucleoside analogue TAS-109 is incorporated into DNA and directly inhibits the activity of

DNA polymerase, which may result in inhibition of DNA replication and cell cycle arrest in the $\mathrm{S}$ and G2/M phases, DNA fragmentation, and tumor cell apoptosis. 